dr. Roatiş Marius Dinu, medic specialist chirurgie plastică microchirurgie reconstructivă, Secția Chirurgie Plastică, Spitalul Județean de Urgență Satu Mare

\title{
Sumar
}

În acest articol voi prezenta reconstrucția şi restabilirea funcției nervului peronier profund în cazul unei tinere de 18 ani care în urma unui traumatism prin muşcătură de câine a rămas cu un defect de nerv peronier comun drept şi deci cu paralizia secundară a acestuia. Consecințele funcționale ale paraliziei acestui nerv sunt severe, în sensul că apar tulburări de mers datorită lipsei de dorsiflexie a piciorului („,picior în picătură”) şi anestezie cutanată în teritoriul său de distribuțiie. Tehnica folosită este cea a transpoziției (neurotizării) unui nerv motor indemn la capătul distal al nervului peronier profund secționat.

Cuvinte cheie: neurotizare, nerv peronier profund, transfer de nerv, nerv peronier superficial.

Lipsa de dorsiflexie a piciorului are consecințe severe în activitatea de zi cu zi, cea profesională şi recreațională. Aceasta este produsă prin lezarea nervului peronier comun, a ramurii sale profunde sau a plexului lombar la nivelul rădăcinilor L4 şi L5. Datorită traiectului său relativ superficial în porțiunea proximală, NPC este vulnerabil la leziuni produse prin compresie, traumatisme sau întindere. Manifestările clinice ale leziunii de nerv peronier comun sunt: tulburări de mers (mersul stepat) datorită lipsei de dorsiflexie a piciorului („picior în picătură”), parestezii sau anestezie la nivelul tegumentului feței anterolaterale a gambei, gleznei şi feței dorsale a piciorului.

\section{Caz clinic}

Pacienta în vârstă de 18 ani a suferit în urmă cu 3 luni un traumatism prin muşcătură de câine la nivelul spațiului popliteu drept. S-a adresat Spitalului Municipal din localitatea unde domiciliază şi s-a practicat într-o primă etapă debridarea chirurgicală, constatându-se în acelaşi timp un defect de nerv peronier comun drept şi un defect cutanat motiv pentru care în a doua etapă s-a realizat acoperirea defectului cu un lambou local de transpoziție şi plastie cu piele liberă despicată (fig.1). Evoluția a fost nefavorabilă din punct de vedere funcțional, pacienta prezentând tulburări de mers -mers stepat, lipsa de dorsiflexie a piciorului (fig. 2) şi anestezie cutanată la nivelul feței externe a gambei şi feței dorsale a piciorului drept. După 3 luni se adresează serviciului nostru de chirurgie plastică, când după o intervenție chirurgicală de evaluare a stării locale se constată un defect de NPC de aproximativ $6 \mathrm{~cm}$ ş se hotăreşe ca în etapa următoare să se efectueze un transfer de nerv -ramura motorie din nervul tibial destinat muşhiului solear-la capătul distal al ramurii profunde al NPC. 


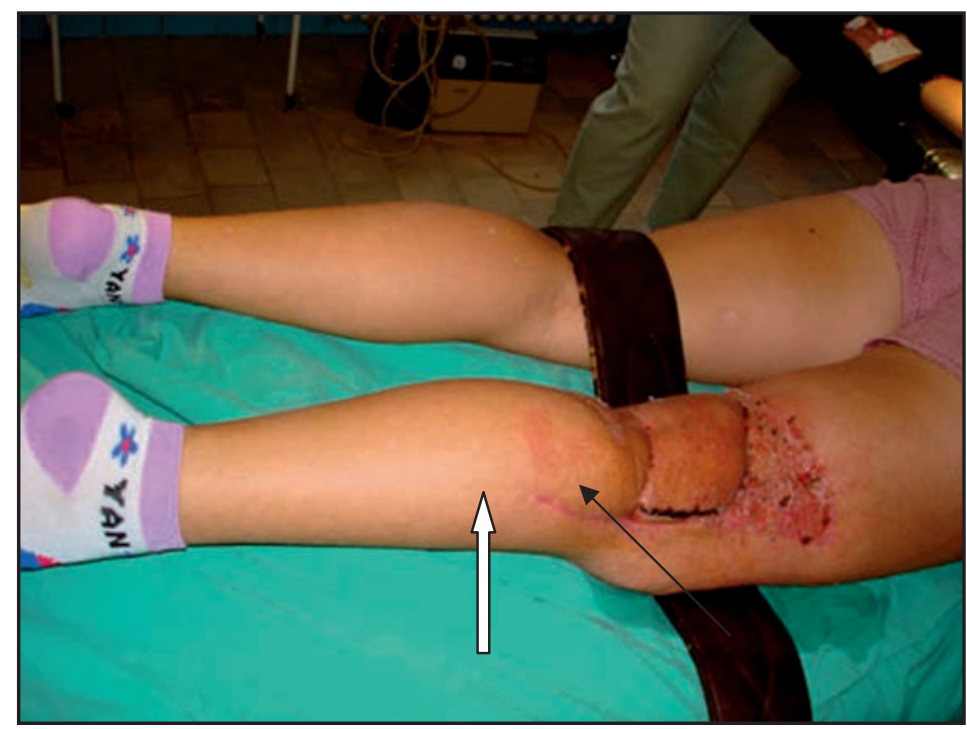

Fig. 1 Înainte de prima intervenție chirugicală de reconstrucție a nervului, la 3 luni de la accident. (Săgeata groasă indică lamboul de transpoziție ce acoperă defectul de nerv, iar săgeata subțire indică grefa de piele)

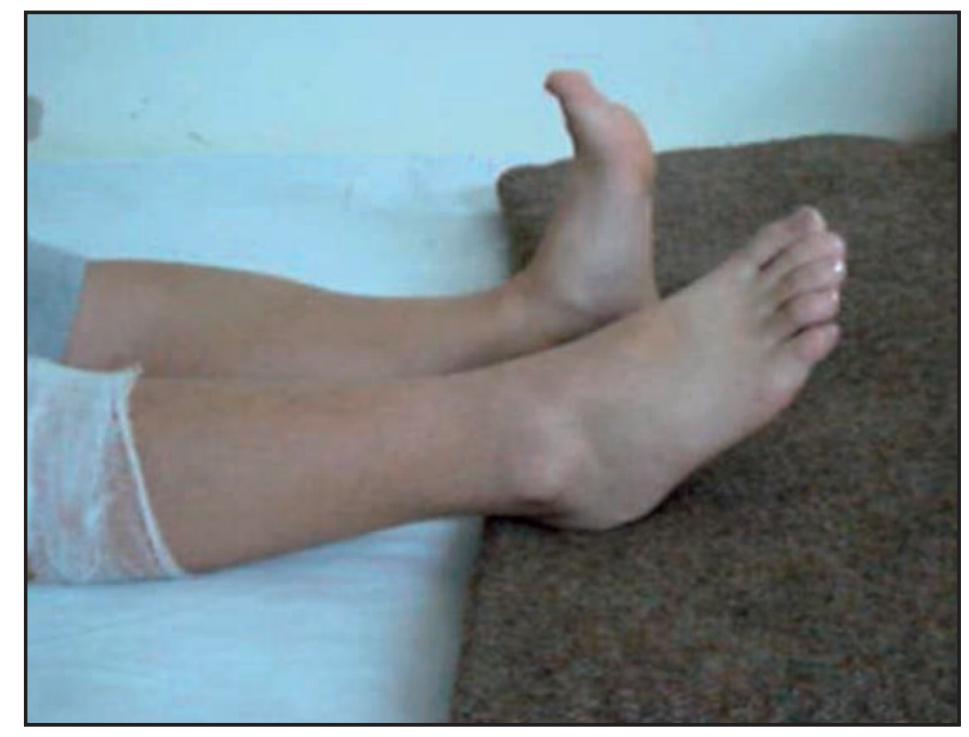

Fig.2 Se observă lipsa de dorsiflexie a piciorului drept (piciorul stâng este flectat dorsal)

\section{Anatomie chirurgicală (fig. 3)}

Nervul peronier comun (NPC) este ramura de bifurcație a nervului sciatic alături de nervul tibial (NT). De la originea sa nervul peronier comun coboară oblic prin fosa poplitee către marginea sa laterală peste muşchiul plantar, apoi înconjoară porțiunea proximală a muşchiului peronier lung având un traiect către porțiunea anterioară a gambei, unde se împarte în cele două ramuri principale: nervul peronier profund (NPP) şi nervul peronier superficial (NPS). Ramura profundă a NPC se divide destul de repede după ce trece pe sub marginea fibroasă a peronierului lung; ramura inițială inervează muşchiul tibial anterior iar cele ulterioare inervează muşchii extensor lung al degetelor, extensor lung al halucelui şi peronierul al treilea. La nivelul piciorului se divide din nou în două ramuri: medială şi 
laterală. Ramura medială se continuă ca ramură senzitivă şi inervează o zonă mică a tegumentului de pe fața dorsală a primului spaţiu interdigital. Ramura laterală inervează muşchiul extensor scurt al degetelor şi muşchiul extensor al halucelui. Nervul peronier superficial (NPS) inervează muşchiul peronier lung şi peronierul scurt coborând între aceştia şi devine mai superficial în trimea distală a gambei pentru ca în fața anterioară a gleznei să se împartă în două ramuri: medială şi laterală. NPS asigură inervația senzitivă a tegumentului anterolateral al gambei şi gleznei şi a feței dorsale a piciorului.

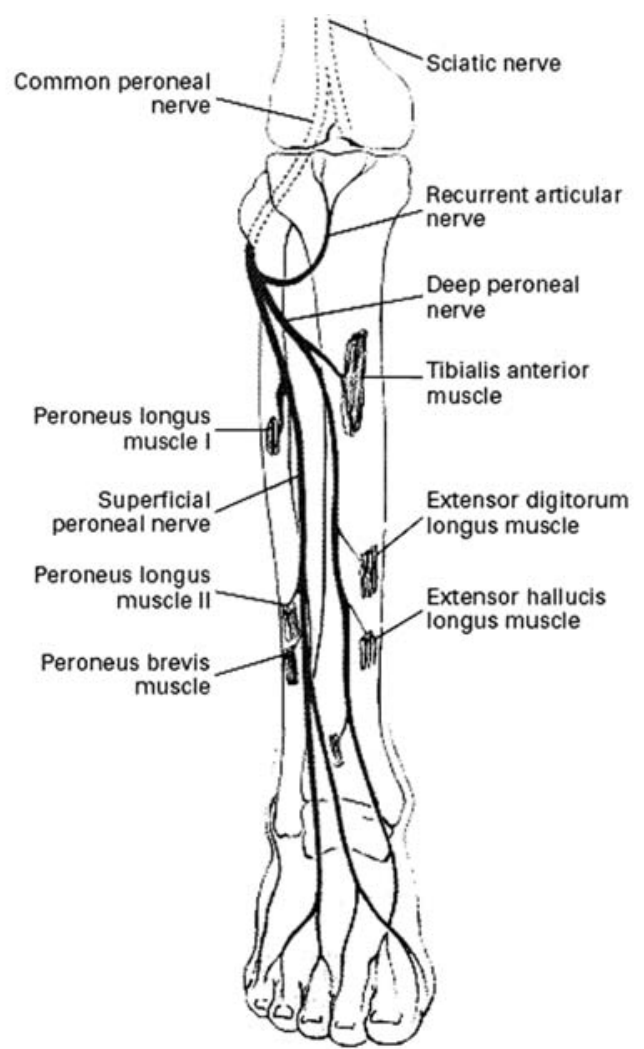

Fig.3 Anatomia NPC

Metodele tradiționale pentru tratamentul paraliziei de nerv peronier comun sunt reprezentate de purtarea unei orteze de gleznă şi picior, transferul de tendon tibial posterior şi tratamentul conservativ prin fizioterapie. Purtarea ortezei nu asigură dorsiflexia activă apiciorului şi este rău tolerată (fig. 4).

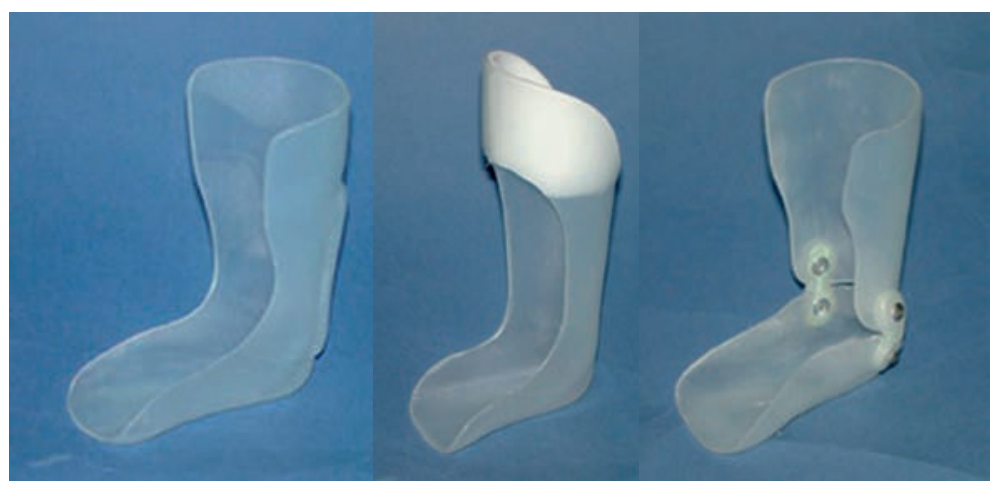

Fig.4 Orteze de gleznă-picior

Transferul de tendon tibial posterior poate îmbunătății dorsiflexia piciorului însă nu în totalitate, dar pe termen lung poate produce picior plat, deformare în valg, artrită. Tratamentul chirurgical standard în cazul defectului de nerv este interpunerea unei grefe de nerv. Rezultatul este de obicei 
nesatisfăcător mai ales dacă defectul de nerv măsoară $>6 \mathrm{~cm}$. Conceptul de transfer de nerv pentru pierderea funcției nervului în leziunile periferice a fost descris la membrul superior. În acest articol descriem recuperarea funcției nervului peronier profund prin transferul unui nerv motor intact din nervul tibial. Neurotizarea în cazul paraliziei faciale sau leziunilor de plex brahial este bine cunoscută şi reprezintă o alternativă foarte bună la transferul de tendoane.

\section{Tehnică chirurgicală}

Operația s-a efectuat în anestezie rahidiană cu pacienta în decubit ventral. S-a practicat o incizie verticală pe fața posterioră a coapsei ce coboară în spațiul popliteu şi se prelungește la nivelul gambei. După decolarea tegumentului se disecă şi se izolează nervii. Se porneşte dinspre proximal şi se merge spre distal, de la nervul sciatic spre cele două ramuri terminale ale sale: NT şi NPC. Se constată un defect de aproximativ $6 \mathrm{~cm}$ pe traiectul nervului peronier comun (NPC), se separă cele două ramuri ale NPC, anume NPP (nervul peronier profund) şi NPS (nervul peronier superficial). Se trece la disecția ramurii motorii destinate muşchiului solear din nervul tibial, disecția se realizează până la nivelul joncțiunii neuromusculare (Fig.5).

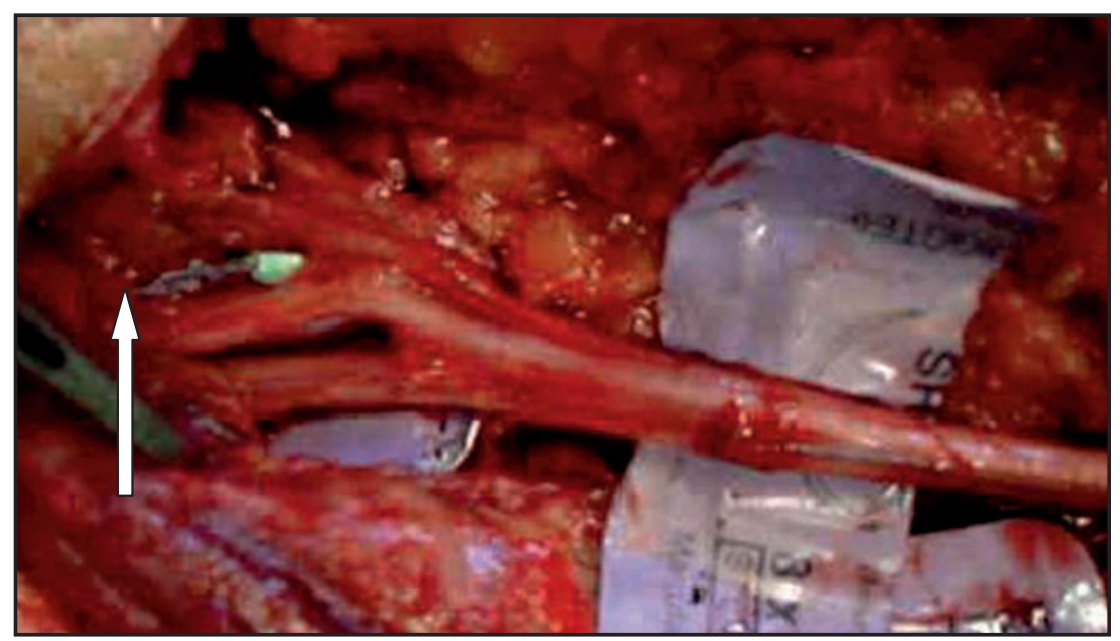

Fig. 5 Nervul tibial (săgeata indică ramura motorie pentru muşchiul solear)

Se secționează ramura motorie pentru solear şi se transpune la capătul distal al NPP (fig.6)

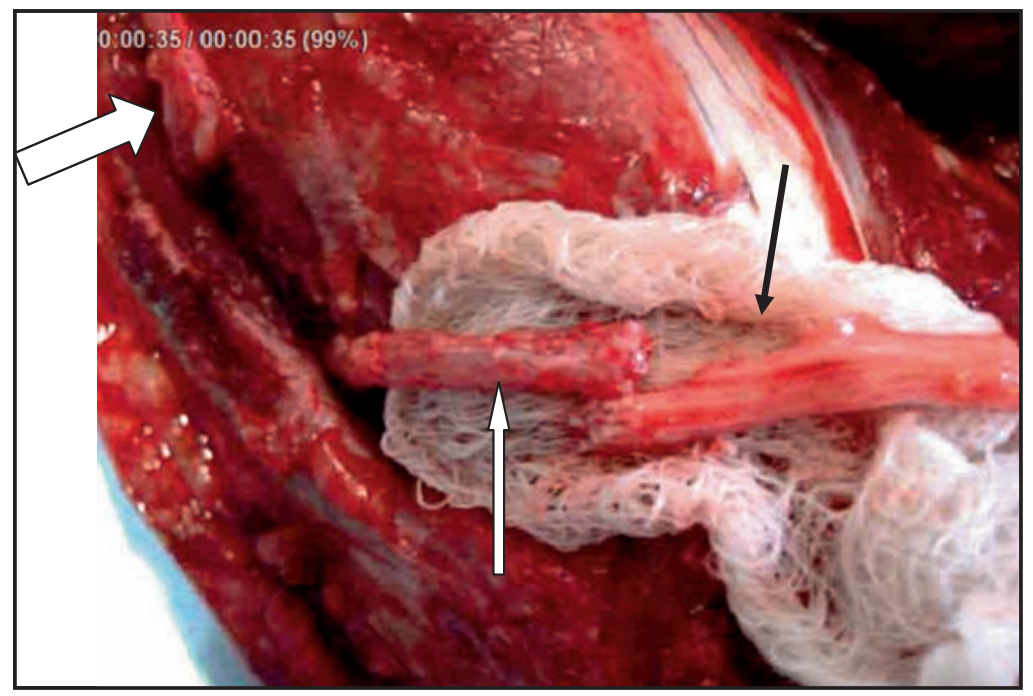

Fig.6 Cele două capete ale nervilor (săgeata albă indică capătul distal al NPP, săgeata neagră indică ramura motorie pentru muşchiul solear, săgeata albă groasă indică NPS) 
Se practică neurorafia epiperinurală cu fir 9-0 şi apoi se închide plaga după efectuarea unei hemostaze riguroase.

\section{Rezultat}

Rezultatul postoperator a fost excelent, cu recuperare motorie M4 (după British Medical Research Council) şi anume, contracție eficientă împotriva unei rezistențe (Fig. 7, Fig.8). Nu acelaşi lucru se poate spune şi despre sensibilitatea cutanată; ramura superficială anervului peronier comun (NPS) a fost abandonată în detrimentul celei motorii, astfel că pacienta a rămas cu deficit senzitiv în teritoriul de distribuție corespunzător. La scurt timp după operație, datorită deficitului senzitiv pacienta suferă o arsură parcelară de grad IIA care se vindecă spontan în 14 zile.

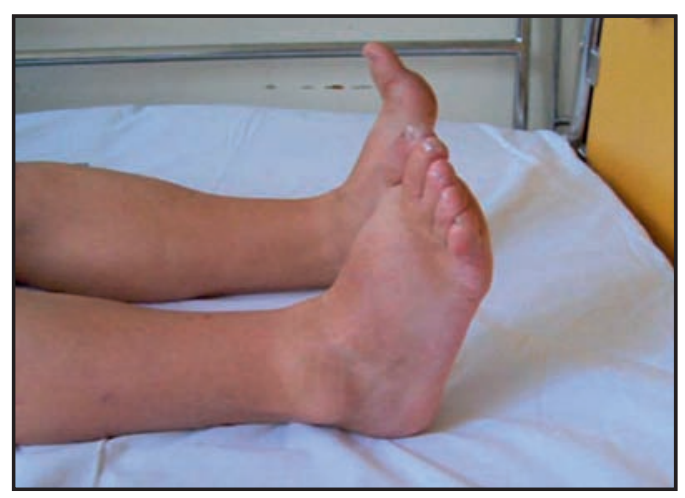

Fig.7 Rezultat postoperator la 8 luni

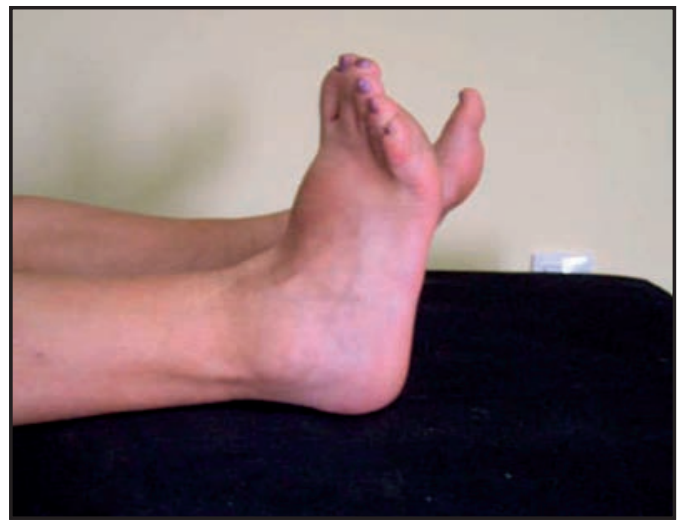

Fig.8 Rezultat postoperator la 10 luni

\section{Discuții}

Transferul de nerv (neurotizarea) este o tehnică bine stabilită ce implică transpoziția segmentului proximal al unui nerv funcțional dar mai puțin important la capătul distal al nervului lezat şi mult mai important funcțional. Acesta va furniza axoni viabili de regenerare pentru reinervarea muțchiului denervat iar axonii transferați îşi vor adapta funcția la noul teritoriu. Această tehnică este larg utilizată la membrul superior precum şi la față în paralizia de nerv facial când se face transferul de nerv hipoglos la nervul facial şi are cîteva avantaje faţă de transferul de tendoane.

Grefa de nerv, ca alternativă la transferul de nerv, nu este lipsită de sechele importante cum ar fi ciacatricea sau formarea de nevrom dureros. Mai mult datorită existenței a celui de-al doilea loc de sutură, rezultatul postoperator este nesatisfăcător. 
Rezultatele sunt foarte bune în cazul transferului de nerv dacă se utilizează ramura motorie pentru solear sau gastrocnemian şi dacă leziunea este mai mică de 8 luni.

Asemănarea cu transferul de tendon este faptul că se pierde inevitabil funcția în teritoriul donor. În cazul transferului de tendon tibial posterior se poate ajunge la pierdera boltei plantare cu apariția picorului plat, iar în cazul transferului de fascicul nervos din nervul tibial se ajunge la o diminuare a circumferinței gambei respective datorită denervării musculare.

Trebuie menționat de asemenea că nu s-a semnalat nici o perturbare a funcției muşchiului inervat de nervul transferat, după cum nu s-a semnalat nici formarea vreunui nevrom.

Limitarea utilizării transferului de nerv este reprezentată de factorul timp; principiul fiziologic de bază al muşchiului scheletic denervat este că denervarea completă mai mult de 1 an la adult va conduce la oparalizie refractară şi permanentă a grupului muscular implicat. Acest fapt corelat cu viteza lentă de creştere a nervului (aproximativ $1 \mathrm{~mm}$ pe zi) impune ca transferul de nerv să fie efectuat în primele 8-12 luni de la debutul paraliziei. Denervarea mai mare de 12 luni reprezintă o contraindicație.

\section{Bibliografie}

1. Birch R, Bonney G, Wynn Parry CB: Surgical Disorders of the Peripheral Nerves. London: Churchill Livingstone; 1998

2. Garozzo D, Ferraresi S, Buffatti P.: Surgical treatment of common peroneal nerve injuries: indications and results. A series of 62 cases. J Neurosurg Sci 2004;48:105-112; discussion 112

3. Ferraresi S, Garozzo D, Buffatti P.: Common peroneal nerve injuries: results with one-stage nerve repair and tendon transfer. Neurosurg Rev 2003;26:175-179

4. Rahul K. Nath, M.D.,1 Andrew B. Lyons, B.Sc.,1 and Melia Paizi, D.Sc: Successful Management of Foot Drop by Nerve Transfers to the Deep Peroneal Nerve, Journal of reconstructive microsurgery/volume 24, number 6, 2008

5. Jamal Gousheh, M.D., Alireza Babaei: A New Surgical Technique for the Treatment of High Common Peroneal Nerve Palsy, Plastic and Reconstructive Surgery, March 2002

6. M. Buyukmumcu, M. E.U,Stun, M. S: Eker, Y. Kocaogullari and A. Sagmanligil: The possibility of deep peroneal nerve neurotisation by the superficial peroneal nerve: an anatomical approach, J. Anat. (1999) 194, pp. 309-312

7. Kale D. Bodily, Robert J. Spinner, Allen T. Bishop: Restoration of Motor Function of the Deep Fibular (Peroneal) Nerve by Direct Nerve Transfer of Branches from the Tibial Nerve: An Anatomical Study, Clinical Anatomy, 17:201-205, (2004) 